\title{
Cluster analysis for food group consumption patterns in a national sample of Palestinian schoolchildren: Evidence from HBSC Survey 2013-2014
}

\section{RESEARCH}

\author{
Radwan Qasrawi 1,*, Diala Abu Al Halawa', Rawan Ayyad ', Halema Al Sabbah², Haneen Taweel ', and \\ Ziad Abdeen ${ }^{3}$ \\ ${ }^{1}$ Department of Computer Science, Al-Quds University, Jerusalem, Palestine. \\ ${ }^{2}$ College of Natural and Health Sciences, Zayed University, United Arab Emirates \\ ${ }^{3}$ Al-Quds Public Health Society, Jerusalem, Palestine
}

\section{A B S T R A C T}

Background: Promoting a healthy diet and lifestyle to reduce the national burden of nutrition-related problems among Palestinians requires an understanding of food consumption trends and patterns. Few studies have examined the food consumption patterns with the macro and micronutrient intakes and nutrition risk factors. The objective of this study was to study the food frequency and nutrient intake consumption patterns of Palestinian schoolchildren and their associations with the socioeconomic and risk factors. This is a national cross-sectional descriptive study conducted on Palestinian schoolchildren from the West Bank. The study examined the food consumption patterns of the macro and micronutrient intakes and nutrition risk factors among 1945 students aged 11-16 years. The data collected using the food frequency questionnaire and 24-hour recall that was administered by trained field workers. Food groups' classification, nutrient intakes, body mass index (BMI) Z-scores, and socioeconomic differences were examined across the food groups' patterns of consumption. We employed Z-score and K-Means cluster analysis to identify food consumption patterns and to examine factors associated with nutrient intakes. The food frequency results identified three food consumption clusters including the traditional, non-traditional, and mixed pattern. A total of 796 students (41\%) were in traditional cluster, 458 (23.5\%) in non-traditional cluster, and 691(35.5\%) in mixed cluster. The nutrient intakes identified three clusters (High, Moderate, and Low consumption patterns) out of macronutrient, vitamins, and minerals categories. Most of the students located in the low consumption cluster for macronutrient, vitamins, and minerals clusters (66.9\%, $67.7 \%$, and $64 \%$ ) respectively. The traditional cluster was associated with healthy, non-obese, and physically active students and the non-traditional cluster was associated with unhealthy and obese students, but both shown significantly different across the identified clusters. Imbalance in dietary intakes among schoolchildren reflects a lack of dietary diversity. High sugar, fats and oils, and beverages consumption, low consumption of grains, fruits, beans and legumes, and meat are noticed in Palestinian schoolchildren. The findings indicated the importance of considering the food groups' intake variations among Palestinian schoolchildren. As the segments relate to children's health, nutrition diet programs should consider the high scores of non-traditional and mixed food consumption among schoolschildren.

Keywords: Cluster analysis; consumption patterns; nutrients; socioeconomic status; diet, food group patterns, schoolchildren.

* Correspondence:

Email: radwan@staff.alquds.edu

Tel.: +972592660417

(c) copy rights 2021: All materials in this article is protected, permission requests should be addressed Al-Quds University. www.alquds.edu

\section{Introduction}

Diet and lifestyle are major determinants of the health and development of chronic diseases. An unhealthy diet and sedentary lifestyle contribute to the increasing prevalence of obesity and non-communicable diseases like diabetes, hypertension, and cardiovascular 
diseases, especially when adopted in childhood and early adolescence.(Farpour-Lambert et al. 2015; Mehio Sibai et al. 2011; Nishtar, Gluckman, and Armstrong 2016; Waters et al. 2014; James 2008). The consumption of an unhealthy diet is becoming more frequent due to the global rapid food intake transition (Salameh et al. 2014). This transition affecting the developing countries including Palestine. Change in socioeconomic status is associated with a transition in food consumption patterns across developing countries, where traditional healthy diets, including the Mediterranean diet, are being changed into more westernized dietary patterns. Moreover, in -society economic variation displays a difference in food consumption patterns. Individuals with high income consume more meat, poultry, fruits, and vegetables than those with lower income, who consume more saturated fats and carbohydrates(Heng and House 2018; Grieger, Scott, and Cobiac 2012; Nguyen et al. 2013; Alavian et al. 2008; Salameh et al. 2014). Schoolchildren and adolescents have been affected by the food consumption transition, a shift in diet consumption pattern is observed including high consumption rate of energy drinks, soft drinks, fast food, sweets and chocolates, and low consumption rate of fruits, and vegetables(Al et al. 2009; Aounallah-Skhiri et al. 2011; Williamson et al. 2020; Mehio Sibai et al. 2011). Several studies show that nutrition transition caused a high increase in childhood overweight and obesity rates. It has been found that unhealthy food is the leading source of calories, while healthy food such as fruits and vegetable intakes has decreased(Rahman et al. 2020; Aounallah-Skhiri et al. 2011; Williamson et al. 2020). Palestine is also subjected to nutritional transition (Abdeen et al. 2012; Aboul-Enein, Bernstein, and Neary 2017; Nubani-Husseini et al. 2016; Mikki et al. 2009). Similar to eastern Mediterranean countries, Palestine reported a high prevalence of overweight and obesity rates(Elessi and Albaraqouni 2019).

There are limited data on dietary intakes of Palestinian schoolchildren. Several studies have been conducted for assessing Palestinians eating habits, food consumption, and lifestyle including schoolchildren (Roblin 2007; Shah et al. 2019; Tariq, Shahid, and Tariq 2018; Zhou et al. 2016; NubaniHusseini et al. 2016; Aboul-Enein, Bernstein, and Neary 2017). Investigation of transitions in food consumption and their relation to various sociodemographic variables is of paramount importance to analyze determinants of health and wellbeing among the population. Moreover, focusing on children and adolescents is important as this period is critical for adopting lifelong health behaviors. To date, limited information is available on food groups' consumption patterns among Palestinian schoolchildren. No published studies were found in which the food groups' consumption patterns were clustered and analyzed. This study acts as the first baseline study in which energy and nutrient intakes, lifestyle, and socioeconomic variables are compared according to dietary patterns for schoolchildren.

In Palestine, there is also limited information on the food groups' types and frequency that schoolchildren consume over a single week using FFQ data and over a single day using 24-hour recall data. Therefore, the present study aimed to (i) define the dietary clusters based on the frequency of consumption of food groups across a single week; (ii) define dietary clusters based on food group consumption across single day using 24-hour recall data (iii) compare energy and nutrient intakes clusters and lifestyle and physical activity variables between clusters.

\section{Methods}

Data were obtained from the national survey conducted in West Bank as a part of the Health Behavior in School aged Children (HBSC) survey in 2013-2014. The study aimed at improving the nutrition, physical and mental health of Palestinian children. Study subjects are Palestinian students in grades 5-9 (age 11-16) who were randomly selected from 100 schools in West Bank. The schools were randomly selected and stratified by school 
type (55\% Public and 45\% UNRWA) and weighted according to population size. A random sample of 2000 students was selected from the baseline database weighted for gender and grades, out of 2000 students, 1945 students have accomplished the study criteria, the 55 students were excluded due to the incomplete data variables. Sampling procedures and methods have been described elsewhere in detail (Ziad Abdeen et al. 2018). The study received ethical approval from the Ministry of Education and Al-Quds University Institutional Review Board (IRB). The data were collected, entered, and cleaned by the Ministry of Education under the supervision of Al-Quds Nutrition and Health research institute (ANAHRI) at Al-Quds University.

\section{Measure}

The main outcomes of this analysis were the clusters of food consumption based on food frequency data and food intake and nutrient analysis. Dietary intake information was collected using face to face 24-hour food recall of one day intake and the validated food frequency questionnaire (FFQ) (Mikki et al. 2010). The 24hour recall includes in-depth information about the food consumed during the last 24 hours. The participants were asked to recall the detailed descriptions of each food item consumed over the last $24 \mathrm{~h}$ including the quantity, time, and cooking descriptions. The food consumption quantities were identified using the recipes consumption weight book developed by ANAHRI. The participants' food intakes were entered and analyzed using the Nutribase V.9(Lee 1997), USDA, and the Palestinian Food Recipes databases. The Nutrient intake (Macro and Micronutrients) were computed using the Nutribase V.9 software. The dietary data collected from the 24-hour food recall generated a very large number of foods. The food items and recipes were classified according to the USDA food groups. Overall, the consumed foods were classified into standard food groups. The recipes were grouped by their main ingredients and depending on the ingredient that has the highest caloric value the food group was determined. As before this, the food group categorization methodology was determined based on a previous paper depending on the macronutrient composition of a food item, and 13 groups were set for this research purpose(Ahuja et al. 2012).

The classification produced 13 food groups: 1) vegetables; 2) fruits; 3) grains; 4) meat; 5) poultry and eggs; 6) fish and seafood; 7) beans and legumes; 8) dairy products; 9) sugar and sweets; 10) beverages; 11) fat and oils; 12) nuts and seeds; 13) Miscellaneous or others.

For the food frequency data, the food items were grouped into 8 categories based on similarity in nutrient profile (Frank et al. 1992). These categories were: 1) vegetables; 2) fruits; 3) milk and other dairy products; 4) sweets and chocolate; 5) soft drinks; 7) beverages (Juices with sugar); 8) energy drinks. Response categories were (1)never, (2) 1-2 times a week, (3) 3-4 times a week, and (4) 5-7 times a week (almost daily). As part of the HBSC survey, healthy and unhealthy nutritional practices were assessed using a frequency scale to obtain information on the nutritional status and variations among schoolchildren. Three items were considered indicators of "healthy nutritional practices", these items included the frequency of consumption of fruits, vegetables, and milk, respectively. Three other items were considered indicators on "unhealthy nutritional practices", these included frequencies of consumption of sweets, soft drinks, sugary juices, and energy drinks. Consumption frequency for all items was obtained over a week's duration.

The Demographic and other risk factors variables were collected using the HBSC unified tool(Al et al. 2009). The nutrient values were analyzed and compared to the USDA recommended Allowances (RDA) values for children aged 11-16 years old. The in-class administrative interview method was used for collecting the data. Students reported high response rates (97\%) after excluding the cases with missing data. 


\section{Cluster Analysis}

To identify dietary consumption patterns, we applied the K-Means clusters analysis to the data from the FFQ and the 24-hour recall. The consumption patterns were analyzed using the K-Means clustering algorithm for finding the segments of participants' food consumption. The K-means clustering defined the segments of data sets and assigned each observation into one $\mathrm{K}$ - distinct cluster, the algorithm identified the smallest variation within each data cluster, and the numbers of clusters were repeated until we found the best clustering match with the minimized square error between empirical means of the cluster and the points in the cluster. To identify the FFQ and energy and nutrient intakes clusters with similar patterns, the z-scores were calculated to standardize the nutrient data before clustering.

A non-hierarchical k-Means clustering procedure was used, with the random seed and 10 iterations to refine and optimize the classifications. The final cluster solution was selected based on interpretability and the percent of the study population in each cluster.

\section{Statistical analysis}

The statistical analysis was conducted using the IBM Statistical Package for Social Science V21. Furthermore, the dietary consumption patterns were analyzed for each cluster and descriptive comparison analysis was conducted between the consumption clusters for finding the patterns and the differences between clusters. K-Means cluster analysis was performed using SPSS V21. for Windows.

Chi-squared tests were used to assess differences between categorical data. Continuous data were assessed for normality and, if required, normalized with natural log transformation. Oneway analysis of variance (ANOVA) was used to test for significant differences in mean nutrient and gram intakes between the clusters.

\section{Results}

Characteristics of respondents

The description characteristics of the study sample are presented in Table 1. A total sample of 1945 students was collected from the West Bank, Palestine. Among these participants around (47\%) boys and (52.7\%) girls. The mean age was 13.5 years, ranging from 11 to 16 years. The sample was selected from Public and UNRWA (Refugee) Schools. UNRWA represented (45\%), and public schools represent (55\%) of the study sample.

Table 1: The sample characteristics of schoolschildren 11-16 years old by gender.

\begin{tabular}{|c|c|c|c|}
\hline Age in Years & Boys $(n=920)$ & $\begin{array}{c}\text { Girls(n=1025) } \\
\text { n (\%) }\end{array}$ & Total \\
\hline $11-12$ & (38.6)355 & $(40.4) 414$ & (39.5)769 \\
\hline $13-14$ & (38.6)355 & (37.7)386 & $(38.1) 741$ \\
\hline 15- 16 & (22.8)210 & (22)225 & $(22.4) 435$ \\
\hline \multicolumn{4}{|l|}{ School Type } \\
\hline Public & (48.7)448 & $(60.9) 624$ & (55.1)1072 \\
\hline UNRWA & (51.3)472 & $(39.1) 401$ & (44.9)873 \\
\hline \multicolumn{4}{|l|}{$\begin{array}{l}\text { Economic } \\
\text { Status }\end{array}$} \\
\hline Low Income & (38)350 & (31.7)325 & $(34.7) 675$ \\
\hline $\begin{array}{l}\text { Moderate } \\
\text { Income }\end{array}$ & (52.9)487 & (57)584 & (55.1)1071 \\
\hline High Income & (9)83 & (11.3)116 & (10.2)199 \\
\hline \multicolumn{4}{|l|}{ Living Place } \\
\hline Refugee & $(41.7) 384$ & $(27.4) 281$ & $(34.2) 665$ \\
\hline Non-Refugee & (58.3)536 & $(72.6) 744$ & (65.8)1280 \\
\hline \multicolumn{4}{|l|}{$\begin{array}{l}\text { Father Educa- } \\
\text { tion }\end{array}$} \\
\hline $\begin{array}{l}\text { Secondary => } \\
\text { School }\end{array}$ & $(62.1) 323$ & (69)459 & (66)782 \\
\hline $\begin{array}{l}\text { Secondary }< \\
\text { School }\end{array}$ & (37.9)197 & (31)206 & (34)403 \\
\hline \multicolumn{4}{|l|}{$\begin{array}{l}\text { Mother Edu- } \\
\text { cation }\end{array}$} \\
\hline $\begin{array}{l}\text { Secondary => } \\
\text { School }\end{array}$ & $(62.3) 294$ & $(71.1) 468$ & $(67.4) 762$ \\
\hline $\begin{array}{l}\text { Secondary < } \\
\text { School }\end{array}$ & (37.7)178 & (28.9)190 & $(32.6) 368$ \\
\hline
\end{tabular}


Results in Table 2 show the lifestyle patterns of schoolchildren; the physical activity lifestyle was categorized into three levels (Low activity, Active and High activity) (17.1\%, 56.5\%, and 26.5\%) respectively. Boys reported higher activity levels than girls $(38 \%, 16 \%)$ respectively. About (72\%) of boys spending more than 1 hour/day leisure time activity, compared to (68\%) of girls spending $>1 \mathrm{H} /$ day. Students reported higher poor healthy food than good healthy food consumption (53\%, 47\%) respectively. About (10\%) of students smoking Nargila or cigarettes, boys were higher smokers than girls $(14.7 \%, 5.5 \%)$ respectively. About (14\%) of students were overweight and obese.

Table 2: Lifestyle characteristics of schoolchildren by gender.

\begin{tabular}{|c|c|c|c|}
\hline Item & $\operatorname{Boys}(n=920)$ & $\begin{array}{c}\text { Girls }(n=1025) \\
n(\%)\end{array}$ & Total \\
\hline \multicolumn{4}{|c|}{ Physical activity } \\
\hline Low activity & $89(9.7)$ & $243(23.7)$ & $332(17.1)$ \\
\hline Active & $480(52.2)$ & $618(60.3)$ & $1098(56.5)$ \\
\hline High activity & $351(38.2)$ & $164(16)$ & $515(26.5)$ \\
\hline \multicolumn{4}{|l|}{$\begin{array}{l}\text { Leisure } \\
\text { time activity }\end{array}$} \\
\hline$<1$ hour/day & $256(27.8)$ & $368(35.9)$ & $624(32.1)$ \\
\hline 1-2hours/day & $396(43)$ & $447(43.6)$ & $843(43.3)$ \\
\hline \multicolumn{4}{|l|}{$\begin{array}{l}\text { Healthy } \\
\text { Food } \\
\text { Consumption }\end{array}$} \\
\hline Poor & $508(55.2)$ & $522(50.9)$ & $1030(53)$ \\
\hline \multicolumn{4}{|l|}{ Smoking } \\
\hline Yes & $135(14.7)$ & $56(5.5)$ & $191(9.8)$ \\
\hline No & $785(85.3)$ & $969(94.5)$ & $1754(90.2)$ \\
\hline \multicolumn{4}{|l|}{ BMI } \\
\hline Underweight & $62(6.7)$ & $45(4.4)$ & $107(5.5)$ \\
\hline Normal & $764(83)$ & $804(78.4)$ & $1568(80.6)$ \\
\hline Overweight & $66(7.2)$ & $122(11.9)$ & 188(9.7) \\
\hline Obese & $28(3)$ & $54(5.3)$ & $82(4.2)$ \\
\hline
\end{tabular}

The prevalence of overweight and obesity among boys and girls was (7.2\%, 3\%), and (12\%, $5.3 \%)$ respectively. More than half of participants (55\%) had moderate family income; (34.7\%) had low family income and (10.2\%) had high family income. In terms of living place, about (34.2\%) living in refugee, and (65.8\%) in non-refugee residence. Students reported the father and mother education with higher than secondary school were (66\% and 67.4\%) respectively, while father and mother education less than secondary school were (34\% and $32.6 \%$ ) respectively.

Energy and Macronutrient intake and food groups' consumption

The mean energy and macronutrient intake of Palestinian schoolchildren is reported in table 3. The overall mean energy consumption of boys was $2552 \mathrm{Kcal}$ and $2064 \mathrm{Kcal}$ for girls. The average consumption of protein for boys and girls was (89.2g, $69.6 \mathrm{~g})$, respectively. The carbohydrate and fat average consumption for boys and girls were $(360.3 \mathrm{~g}, 292.9 \mathrm{~g})$ and $(87.4 \mathrm{~g}, 71.4 \mathrm{~g})$ respectively. The mean vitamins and minerals intake of Palestinian schoolchildren reported in Table 4 . In the case of vitamins, boys is reported higher average consumption than girls in vitamin B1, B2, B3, B5, B6, B9, and B12 ((0.8,0.7); (1.2,0.9); (13.6,11.2); (3.9,3.1); (1.6,1.2); (273.4, 243.2); (301.1, 243.2); (3.3, 2.5)) (boys, girls) respectively.

The girls reported higher consumption of vitamin $A$ and $C$ than boys ((5.2, 5); ( $113.8,99.6)$ ) respectively. In the case of mineral consumption, boys reported higher average mineral consumptions including Calcium, Magnesium, Phosphorus, Potassium, Sodium, Iron, Manganese and Zinc. The boys in the age group (13-14 years) had a higher mineral consumption among boys. While girls in the age group 11-12 years had higher mineral consumption among girls. 
Table 3: Mean (SE) of daily Intake of Energy and Macronutrients of Palestinian Schoolchildren.

\begin{tabular}{|c|c|c|c|c|c|c|c|c|}
\hline \multirow[t]{2}{*}{ Macronutrient } & \multicolumn{4}{|c|}{ Boys $(n=920)$} & \multicolumn{4}{|c|}{ Girls(n=1025) } \\
\hline & $11-12$ & $13-14$ & $15-16$ & All Ages & $11-12$ & $13-14$ & $15-16$ & All Ages \\
\hline Calories (Kcal) & $2475(792.3)$ & $2645.8(1109.9)$ & $2525.4(843.3)$ & $2552.4(940.2)$ & $2133.9(712)$ & $2025.3(725.6)$ & $2002.5(720.6)$ & $2064.2(720.7)$ \\
\hline Protein(g) & $87.6(35.8)$ & $92(36.9)$ & $87.5(38.1)$ & $89.2(36.8)$ & $72.2(30.1)$ & $67.4(30.5)$ & $68.6(31.6)$ & $69.6(30.6)$ \\
\hline$\%$ Protein & $14(3.7)$ & $13.8(3.5)$ & $13.7(3.6)$ & $13.9(3.6)$ & $13.3(3.5)$ & $12.9(3.2)$ & 13.4(3.8) & $13.2(3.5)$ \\
\hline Carbs(g) & $346.9(117.5)$ & $376(230.3)$ & $356.6(127.2)$ & $360.3(172)$ & $302.4(101.6)$ & $286.8(102.3)$ & $285.7(122.8)$ & $292.9(107)$ \\
\hline$\%$ Carbs & $55.8(8.7)$ & $55.6(8.2)$ & $56.3(8.8)$ & $55.9(8.5)$ & $56.5(7.9)$ & $56.5(7.9)$ & $56.5(8.9)$ & $56.5(8.1)$ \\
\hline Fat(g) & $85.2(37.3)$ & $90.4(36.3)$ & $85.9(38.2)$ & $87.4(37.2)$ & $73.8(33.1)$ & $70.9(32.9)$ & $68(27.5)$ & 71.4(31.9) \\
\hline \%Fat & $30.2(7.4)$ & $30.5(7.3)$ & $30(7.8)$ & $30.3(7.4)$ & $30.1(6.8)$ & $30.6(6.8)$ & $30.1(7.5)$ & $30.3(7)$ \\
\hline SatFat(g) & 21.4(10.9) & $23.4(11.7)$ & $22.8(11.8)$ & $22.5(11.4)$ & $20.1(10.5)$ & $19.2(11.3)$ & 18.1(9.3) & $19.3(10.6)$ \\
\hline TransFat(g) & $0.3(0.8)$ & $0.3(0.8)$ & $0.2(0.8)$ & $0.3(0.8)$ & $0.3(0.9)$ & $0.3(0.9)$ & $0.4(1.1)$ & $0.3(1)$ \\
\hline TransMonoFat(g) & $0.1(0.3)$ & $0.1(0.5)$ & $0(0.3)$ & $0.1(0.4)$ & $0.1(0.3)$ & $0(0.2)$ & $0.1(0.3)$ & $0.1(0.3)$ \\
\hline MonoFat(g) & $31.9(20)$ & $33.6(18.9)$ & 29.4(19) & $32(19.4)$ & $26.5(15.7)$ & $24.8(15.4)$ & $23.8(12.2)$ & $25.3(14.9)$ \\
\hline PolyFat(g) & $17.9(10.1)$ & $19(9.7)$ & $19.6(10.9)$ & $18.7(10.1)$ & 15.6(8.8) & $15.2(8.4)$ & $15.6(8.3)$ & $15.4(8.5)$ \\
\hline
\end{tabular}

Carbs: Carbohydrates, SatFat: Saturated Fatty Acids, TransFat: Trans-Unsaturated Fatty Acids, MonoFat: Monosaturated Fatty Acids, PolyFat: Polysaturated Fatty Acids.

\section{Cluster Analysis}

The food group consumption patterns were identified using the K-Means cluster analysis method. Several runs were conducted to identify the best pattern for nutrient intake and food frequency intake data. The nutrients intake was divided into three groups (macronutrient, vitamins, and minerals) clusters in addition to the FFQ clusters. The percentage distribution of clusters as described in table 5. Three clusters were found for each category. The FFQ clusters were identified as Traditional, non-Traditional, and Mixed. A total of 796 students (41\%) were in traditional cluster, 458 (23.5\%) in non-traditional cluster, and 691(35.5\%) in mixed cluster. The nutrients intake clusters were identified as high, moderate, and low consumption (g/day or $\mathrm{ml}$ day). Most of the students located in the low consumption cluster for macronutrient, vitamins, and minerals clusters $(66.9 \%, 67.7 \%$, and $64 \%)$ respectively. The students in the moderate clusters were $(26.4 \%, 26.7 \%$, and $26.2 \%)$. The students in the high consumption clusters were $(6.6 \%, 5.6 \%$, and $7.8 \%)$ respectively. The mean consumption of food groups in FFQ clusters is shown in table 6. The traditional cluster had the highest mean intakes of fruits, vegetables, milk, and milk products consumption. The Non-Traditional cluster had the highest mean intake of soft drinks, beverages, and energy drinks. The Mixed cluster had a high mean intake of soft drinks and sweets and chocolate groups. The univariant analysis shows the mean intakes of food groups varied significantly across the clusters. Table 7 shows the mean intakes of nutrients by FFQ clusters. Nutrient intakes varied significantly across the clusters. Students in the 
Table 4: Mean (SE) daily Intake of Micronutrients (Vitamins and Minerals) of Palestinian schoolchildren

\begin{tabular}{|c|c|c|c|c|c|c|c|c|}
\hline \multicolumn{4}{|c|}{ Boys ( $n=920$ ) } & \multicolumn{5}{|c|}{ Girls (n=1025) } \\
\hline $\begin{array}{l}\text { Micro- } \\
\text { nutrient }\end{array}$ & $11-12$ & $13-14$ & $15-16$ & All Ages & $11-12$ & $13-14$ & $15-16$ & All Ages \\
\hline VitA(mcg) & $330.7(67.6)$ & $270.6(41.6)$ & $164.4(12.6)$ & $269.5(30.8)$ & 189.7(32.3) & 178.6(31.1 & $434(152.2)$ & $239.2(37.8)$ \\
\hline VitB1(mg) & $0.8(0)$ & $0.9(0)$ & $0.8(0)$ & $0.8(0)$ & $0.8(0)$ & $0.7(0)$ & $0.7(0)$ & $0.7(0)$ \\
\hline VitB2(mg) & $1.1(0)$ & $1.2(0.1)$ & $1.1(0)$ & $1.2(0)$ & $0.9(0)$ & $0.9(0)$ & $1(0)$ & $0.9(0)$ \\
\hline VitB3(mg) & $13(0.5)$ & $14.2(0.6)$ & $13.4(0.7)$ & $13.6(0.3)$ & $11.1(0.4)$ & $10.8(0.4)$ & $11.8(0.6)$ & $11.1(0.2)$ \\
\hline VitB5(mg) & $3.8(0.1)$ & $4.1(0.2)$ & $3.8(0.1)$ & $3.9(0.1)$ & $3(0.1)$ & $3(0.1)$ & $3.3(0.1)$ & $3.1(0.1)$ \\
\hline VitB6(mg) & $1.3(0)$ & $1.7(0.2)$ & $1.6(0.1)$ & $1.5(0.1)$ & $1.1(0)$ & $1.1(0)$ & $1.2(0.1)$ & $1.2(0)$ \\
\hline VitB9(mcg) & $286.5(10.5)$ & $332.1(14.1)$ & $273.4(11.3)$ & $301.1(7.3)$ & $246.2(8.4)$ & 236.4(9) & $243.2(12.6)$ & $241.8(5.5)$ \\
\hline VitB12(mcg) & $3.8(0.6)$ & $3.3(0.3)$ & $2.5(0.2)$ & $3.3(0.3)$ & $2.4(0.3)$ & $2.1(0.3)$ & $3.4(0.6)$ & $2.5(0.2)$ \\
\hline VitC(mg) & $92.1(5.3)$ & $112.5(7.5)$ & $90.8(5.7)$ & $99.6(3.8)$ & $117.1(6.9)$ & $111.6(7)$ & $111.5(9.5)$ & $113.8(4.3)$ \\
\hline $\operatorname{VitD}(I U)$ & $57.8(3.1)$ & $60.9(3.3)$ & $75(5.5)$ & $62.9(2.2)$ & $57.8(3.1)$ & $52.6(3.1)$ & $52.3(4.2)$ & $54.6(1.9)$ \\
\hline Vit(EIU) & $4.5(0.2)$ & $4.9(0.2)$ & $5.1(0.2)$ & $4.8(0.1)$ & $4(0.2)$ & $4(0.2)$ & $4.1(0.2)$ & $4(0.1)$ \\
\hline $\mathrm{Ca}(\mathrm{mg})$ & $679.1(23.4)$ & $692.2(25.1)$ & 653.9(27.6) & $678.4(14.7)$ & 1013.3(386) & 572.4(19.3) & $555.1(25.9)$ & $746.7(156.2)$ \\
\hline $\mathrm{Mg}(\mathrm{mg})$ & $279(8.3)$ & $307.8(14.2)$ & $257.6(9.7)$ & $285.2(6.7)$ & $355(128.4)$ & $216.2(6.1)$ & $212.5(7.2)$ & $271.4(52)$ \\
\hline$P(m g)$ & $1067.3(26.9)$ & $1130.6(28.9)$ & 1021.6(31.6) & $1081.3(16.9)$ & $843.5(18.7)$ & $813.9(21.2)$ & $815.7(26.3)$ & $826.3(12.4)$ \\
\hline $\mathrm{K}(\mathrm{mg})$ & $2192.3(52.5)$ & 2534.6(167) & $2092.8(66.3)$ & $2301.7(69.5)$ & $1938.6(44.9)$ & $1882.5(47.1)$ & $1834.4(56.8)$ & $1894.6(28.3)$ \\
\hline $\mathrm{Na}(\mathrm{mg})$ & $3816.7(81.8)$ & 4180.7(85.3) & $3964.5(108)$ & $3990.9(52.2)$ & $3837(524)$ & $3305.4(75.4)$ & $3154.9(87.6)$ & $3487.1(214)$ \\
\hline $\mathrm{Cu}(\mathrm{mg})$ & $1.5(0)$ & $1.6(0.1)$ & $1.4(0)$ & $1.5(0)$ & $2.6(1.3)$ & $1.2(0.1)$ & $1.3(0.1)$ & $1.8(0.5)$ \\
\hline $\mathrm{Fe}(\mathrm{mg})$ & $20.7(0.8)$ & $21.5(0.8)$ & $17.1(0.9)$ & $20.2(0.5)$ & $17.3(0.6)$ & $15.8(0.7)$ & $14.6(0.6)$ & $16.1(0.4)$ \\
\hline $\mathrm{Mn}(\mathrm{mg})$ & $2.6(0.1)$ & $2.8(0.1)$ & $2.5(0.1)$ & $2.6(0.1)$ & $2.2(0.1)$ & $2.2(0.1)$ & $2.1(0.1)$ & $2.2(0)$ \\
\hline $\mathrm{Zn}(\mathrm{mg})$ & $10.3(0.3)$ & $11.2(0.3)$ & $9.7(0.4)$ & $10.5(0.2)$ & $9.5(1.3)$ & $7.6(0.2)$ & $7.9(0.3)$ & $8.4(0.5)$ \\
\hline \multicolumn{3}{|c|}{ FFQ Clusters } & Boys $(n=920)$ & \multicolumn{2}{|c|}{$\begin{array}{c}\text { Girls }(n=1025) \\
n(\%)\end{array}$} & Total & & \\
\hline \multicolumn{2}{|c|}{ Traditional } & & $323(35.1)$ & \multicolumn{2}{|c|}{$473(46.1)$} & $796(40.9)$ & & \\
\hline \multicolumn{2}{|c|}{ Non-Traditional } & & $267(29)$ & \multicolumn{2}{|c|}{ 191(18.6) } & $458(23.5)$ & & \\
\hline Mixed & & & $330(35.9)$ & \multicolumn{2}{|c|}{$361(35.2)$} & $691(35.5)$ & & \\
\hline \multicolumn{9}{|c|}{ Macro-Nutrients Cluster } \\
\hline \multicolumn{2}{|c|}{ High } & & $57(6.2)$ & \multicolumn{2}{|c|}{$72(7)$} & $129(6.6)$ & & \\
\hline \multicolumn{2}{|l|}{ Moderate } & & $269(29.2)$ & \multicolumn{2}{|c|}{$245(23.9)$} & $514(26.4)$ & & \\
\hline \multicolumn{2}{|c|}{ Low } & & $594(64.6)$ & \multicolumn{2}{|c|}{$708(69.1)$} & $1302(66.9)$ & & \\
\hline \multicolumn{9}{|c|}{ Vitamins Cluster } \\
\hline \multicolumn{2}{|c|}{ High } & & $68(7.4)$ & \multicolumn{2}{|c|}{$41(4)$} & $109(5.6)$ & & \\
\hline \multicolumn{2}{|l|}{ Moderate } & & $296(32.2)$ & \multicolumn{2}{|c|}{$223(21.8)$} & $519(26.7)$ & \\
\hline \multicolumn{2}{|l|}{ Low } & & $556(60.4)$ & 761 & 74.2) & $1317(67.7)$ & Table 5: & Means \\
\hline \multicolumn{3}{|c|}{ Minerals Cluster } & & & & & \multicolumn{2}{|c|}{ clusters analysis for } \\
\hline \multicolumn{3}{|l|}{ High } & $96(10.4)$ & & 5.5) & $152(7.8)$ & FFQ and & utrients \\
\hline Moderate & & & $295(32.1)$ & 254 & 24.8) & $549(28.2)$ & intake fo & \\
\hline Low & & & $529(57.5)$ & 715( & 69.8) & $1244(64)$ & consump & ion. \\
\hline
\end{tabular}


Table 6: Mean (SE) Food Frequency Intake by the cluster.

\begin{tabular}{|c|c|c|c|c|}
\hline $\begin{array}{l}\text { Food } \\
\text { Groups }\end{array}$ & Traditional & $\begin{array}{c}\text { Non- } \\
\text { Traditional }\end{array}$ & Mixed & $\begin{array}{c}\text { F-Test } \\
(P<0.001)\end{array}$ \\
\hline Fruits & $5.5(1.3)$ & $5.1(1.6)$ & $3.6(1.3)$ & 0.0 \\
\hline Vegetables & $5.5(1.3)$ & $4.8(1.6)$ & $3.7(1.4)$ & 0.0 \\
\hline $\begin{array}{l}\text { Milk and Milk } \\
\text { Products }\end{array}$ & $5.1(1.5)$ & $4.1(2.0)$ & $2.8(1.5)$ & 0.0 \\
\hline $\begin{array}{l}\text { Sweets and } \\
\text { Chocolate }\end{array}$ & $4.0(1.6)$ & $4.9(1.8)$ & $3.1(1.5)$ & 0.0 \\
\hline Soft Drinks & $3.2(1.5)$ & $5.9(1.4)$ & $3.5(1.7)$ & 0.0 \\
\hline $\begin{array}{l}\text { Beverages } \\
\text { (Juice with } \\
\text { Sugar) }\end{array}$ & $4.1(1.6)$ & $5.1(1.7)$ & $2.9(1.4)$ & 0.0 \\
\hline Energy Drinks & $1.4(0.8)$ & $4.2(2.2)$ & $1.7(1.3)$ & 0.0 \\
\hline
\end{tabular}

non-traditional cluster show a higher mean intake consumption than other clusters in most of the Nutrients except Calcium, Sodium, Magnesium, and Copper where the mixed cluster reported higher consumptions of calcium, magnesium, sodium, and copper than other clusters.

\section{The consumed grams of food groups}

The mean (SE) grams of food groups consumed by the school students in each cluster are presented in table 8 . Three clusters were identified for the grams consumed by students: The high cluster was 140 (7.2\%) the moderate 556 (28.6\%) and the low cluster 1249(64.2\%). Girls in the three clusters consumed more beans and legumes, sugars and sweet, poultry and eggs, and fats and oils than boys. In the case of high consumption cluster, girls had a higher average consumption of poultry and eggs, beans and legumes, sugars and sweets, and fats and oils.

In the moderate cluster, girls had a higher consumption of fruits, meat, poultry and eggs, fish and seafood, beans and legumes and fats and oils than boys.

In the low consumption cluster, girls had higher vegetable consumption than boys. Significant differences were observed between food groups dietary patterns and gender. Girls' daily consumption of food groups was associated with significantly higher intake than boys in all food groups except fats and oils, nuts and seeds, and miscellaneous, where no significant differences were observed.

\section{Energy and Nutrient intakes of consumed food groups}

The nutrient intakes were divided into three groups: Macronutrients, vitamins, and minerals. The results of Z-score K-Means clusters identified three clusters for each group (High, Moderate and Low). Figure 1 shows the characteristics of macronutrient clusters, the percentage distribution of high, moderate and low clusters is $(7.8 \%, 10.5 \%$, and $81.1 \%)$, respectively. Children aggregated into cluster 1 had high Z-Score of energy, protein, and carbohydrate (2.6, 1.6 and 2.9), respectively. Children in cluster 2 scored moderate Z-score in energy, protein, and fat (0.7, 0.7 and 2.3), and had a negative score for carbs (Z-score $=-0.4$ ). Children in cluster 3 scored negatively on energy, protein, Fats and carbs z-scores were $(-0.4,-0.3$, $-0.3,-0.2)$ respectively.

Characteristics of children described in the different clusters by the consumed food group are described in Figure 2. The macronutrient high cluster pattern (Figure 2a) included high fats and oils consumption (56\%) of the sample and a significantly higher percentage of girls than boys were observed. In the moderate cluster pattern (Figure $2 \mathrm{~b}$ ), children consumed a high percentage of grains (98\%), there were no significant differences regarding gender. In the low cluster pattern (Figure 2c), children consumed more vegetables, sugar, and beverages (15.9\%, 11.7\%, 
Table 7: Mean (SE) of schoolchildren nutrient intake by FFQ clusters.

\begin{tabular}{|c|c|c|c|c|}
\hline Nutrient Intakes & Traditional & Non-Traditional & Mixed & F-Test-P-value \\
\hline Calories(Kcal) & $2354.4(33.3)$ & $2386.5(39.7)$ & $2166.2(29.4)$ & 0 \\
\hline Protein(g) & $80.8(1.2)$ & 82.7(1.9) & $74.1(1.2)$ & 0 \\
\hline Carbs(g) & $332.9(6.2)$ & $335.2(5.7)$ & $308.6(4.5)$ & 0 \\
\hline Fiber(g) & $23.9(0.7)$ & $22.5(0.7)$ & $21(0.5)$ & 0 \\
\hline Fat(g) & $81.4(1.2)$ & $82.8(1.8)$ & $73.7(1.3)$ & 0 \\
\hline Retinol(mcg) & $227.9(27.6)$ & $333(76.7)$ & $230.3(35)$ & 0 \\
\hline VitB1(mg) & $0.8(0)$ & $0.8(0)$ & $0.7(0)$ & 0 \\
\hline VitB2(mg) & $1.1(0)$ & $1.1(0)$ & $1(0)$ & 0 \\
\hline VitB3(mg) & $12.3(0.3)$ & $13.6(0.5)$ & $11.4(0.3)$ & 0 \\
\hline VitB5(mg) & $3.6(0.1)$ & $3.8(0.1)$ & $3.2(0.1)$ & 0 \\
\hline VitB6(mg) & $1.4(0.1)$ & $1.5(0.1)$ & $1.2(0)$ & 0 \\
\hline VitB9(mcg) & $277.3(7.6)$ & 276.5(9.4) & $256.9(7.1)$ & 0 \\
\hline VitB12(mcg) & $2.6(0.2)$ & $3.4(0.3)$ & $2.9(0.4)$ & 0 \\
\hline $\operatorname{VitC}(\mathrm{mg})$ & $117.6(4.9)$ & $106.3(6)$ & $95.6(4.4)$ & 0 \\
\hline $\operatorname{VitD}(I U)$ & $66.8(2.4)$ & $56.7(2.7)$ & $50.3(2.3)$ & 0 \\
\hline Vit(EIU) & $4.4(0.1)$ & $4.6(0.2)$ & $4.3(0.1)$ & 0 \\
\hline $\mathrm{Ca}(\mathrm{mg})$ & $682(15.6)$ & 629.4(19.7) & $808.1(23.2)$ & 0.031 \\
\hline $\mathrm{Mg}(\mathrm{mg})$ & $261.8(7.2)$ & $257.2(7)$ & $310.4(77)$ & 0.005 \\
\hline$P(m g)$ & 974.6(17.1) & $992.7(24)$ & $884.6(16.2)$ & 0 \\
\hline $\mathrm{K}(\mathrm{mg})$ & $2222.6(78.7)$ & 2082.6(46.1) & $1934.1(35.7)$ & 0 \\
\hline $\mathrm{Na}(\mathrm{mg})$ & $3729.8(56)$ & $3685.4(74)$ & $3746.8(31.6)$ & 0 \\
\hline $\mathrm{Cu}(\mathrm{mg})$ & $1.4(0)$ & $1.4(0)$ & $2.1(0.8)$ & 0.017 \\
\hline $\mathrm{Fe}(\mathrm{mg})$ & $18.9(0.5)$ & $18.1(0.7)$ & $17(0.5)$ & 0 \\
\hline $\mathrm{Mn}(\mathrm{mg})$ & $2.5(0.1)$ & $2.4(0.1)$ & $2.3(0.1)$ & 0 \\
\hline Zn(mg) & $9.3(0.2)$ & $9.7(0.3)$ & $9.4(0.8)$ & 0 \\
\hline
\end{tabular}

and 12\%) respectively. Significant differences 1 had high Z-Score of Vit B6, B3, and B5 (2.8, 2.7 regarding gender were observed. Figure 3 and 2.1) respectively. Children in cluster 2 scored shows the characteristics of vitamin clusters, moderate Z-score in B2, B3, and B5 (2.1, 1.3 and the percentage distribution of high, moderate 1.2) and had low score for retinol (Z-score=0.1). and low clusters is (8.1\%, 9.6\%, and 82.3\%), Children in cluster 3 scored negatively on vitB6, respectively. Children aggregated into cluster retinol, B12, B1, B2, B3, and B5 (Z-score =-0.2,-0.07, 
Table 8: The Mean (SE) grams intake cluster by food groups and gender.

\begin{tabular}{|c|c|c|c|c|c|c|c|c|c|c|}
\hline \multirow[b]{2}{*}{ Food Groups } & \multirow[b]{2}{*}{ High } & \multicolumn{2}{|l|}{ Boys } & \multicolumn{3}{|c|}{ Girls } & \multicolumn{3}{|c|}{ Overall } & \multirow[b]{2}{*}{ P-Value } \\
\hline & & Moderate & Low & High & Moderate & Low & High & Moderate & Low & \\
\hline \multirow[t]{2}{*}{ Vegetable } & 823.8 & 366.3 & 111.5 & 806.6 & 360.2 & 113.1 & 814.7 & 363.3 & 112.4 & 0.001 \\
\hline & $(24.2)$ & $(5.4)$ & $(3.7)$ & $(23.9)$ & $(5.1)$ & $(6.1)$ & (17) & (3.7) & $(3.7)$ & \\
\hline \multirow[t]{2}{*}{ Fruits } & 804.7 & 344.5 & 144.4 & 779.4 & 345.4 & 129.3 & 794.3 & 345 & 135.5 & 0.001 \\
\hline & (29.6) & $(7)$ & $(13.8)$ & $(29.3)$ & $(6.3)$ & $(4.1)$ & $(21.1)$ & $(4.7)$ & $(6.1)$ & \\
\hline \multirow[t]{2}{*}{ Grains } & 771.8 & 391.5 & 211.7 & 708.9 & 354.2 & 153.1 & 755.6 & 372.2 & 173.4 & 0.001 \\
\hline & $(15)$ & $(4.6)$ & $(29.5)$ & (19.9) & $(4.1)$ & $(3.4)$ & $(12.4)$ & $(3.1)$ & $(10.6)$ & \\
\hline \multirow[t]{2}{*}{ Meat } & 643.9 & 290.7 & 75.1 & 605.4 & 316.8 & 72.1 & 634.3 & 297 & 73.5 & 0.001 \\
\hline & $(18.4)$ & $(7.9)$ & $(2.9)$ & $(0)$ & $(21.5)$ & (2.7) & $(16.2)$ & $(8)$ & $(2)$ & \\
\hline \multirow[t]{2}{*}{ Poultry and eggs } & 727.2 & 311.7 & 101.2 & 766.2 & 322.5 & 92.4 & 741.1 & 315.6 & 96.6 & 0.001 \\
\hline & $(38.9)$ & $(8.3)$ & $(2.7)$ & (71.3) & (12.8) & $(2.5)$ & $(34.4)$ & $(7)$ & (1.8) & \\
\hline \multirow[t]{2}{*}{ Fish and seafood } & 775 & 293 & 114.1 & 625.3 & 327 & 109.7 & 775 & 308 & 112 & 0.001 \\
\hline & (45) & $(13.6)$ & $(5.7)$ & (0) & $(18.4)$ & (6) & (45) & $(11.3)$ & $(4.1)$ & \\
\hline \multirow[t]{2}{*}{ Beans and legumes } & 631.6 & 303 & 70.4 & 889.9 & 317.7 & 50.2 & 803.8 & 308 & 60.9 & 0.001 \\
\hline & $(11.2)$ & (17.4) & $(2.4)$ & $(2.4)$ & $(27.2)$ & $(2.2)$ & $(86.1)$ & $(14.6)$ & $(1.7)$ & \\
\hline \multirow[t]{2}{*}{ Dairy products } & 724.8 & 337.3 & 92.9 & 694 & 320.7 & 83.7 & 709.4 & 329.8 & 87.7 & 0.001 \\
\hline & $(42.3)$ & $(6.7)$ & $(5.2)$ & $(25.8)$ & $(7.1)$ & $(2.9)$ & $(24.4)$ & $(4.9)$ & $(2.8)$ & \\
\hline \multirow[t]{2}{*}{ Sugars \& sweets } & 425.2 & 278.2 & 37.8 & 1264.8 & 278.1 & 37.4 & 1264.8 & 278.1 & 37.6 & 0.001 \\
\hline & $(15.7)$ & (21.5) & $(1.4)$ & (0) & $(19)$ & $(1.3)$ & $(27.1)$ & $(14.6)$ & $(1)$ & \\
\hline \multirow[t]{2}{*}{ Beverages } & 848 & 362 & 186.8 & 755.8 & 350.5 & 142.9 & 821.6 & 356 & 159.9 & 0.001 \\
\hline & $(20.7)$ & $(6.1)$ & $(26.1)$ & $(20.8)$ & $(5.7)$ & $(3.4)$ & $(16.3)$ & $(4.2)$ & $(10.4)$ & \\
\hline \multirow[t]{2}{*}{ Fats \& oils } & 328.4 & 256.5 & 47.5 & 468.1 & 390.7 & 35.9 & 382.2 & 290 & 41.6 & 0.07 \\
\hline & $(18.2)$ & (17.4) & $(1.1)$ & $(18.7)$ & $(63.9)$ & $(0.8)$ & $(11.3)$ & $(28.1)$ & $(0.7)$ & \\
\hline \multirow[t]{2}{*}{ Nuts \& seeds } & 29.1 & 18.2 & 11.6 & 24.1 & 15.3 & 10.4 & 26.1 & 23.4 & 11 & 0.085 \\
\hline & (19.4) & $(0.6)$ & $(0.9)$ & $(0.9)$ & $(0.8)$ & $(0.7)$ & $(0.6)$ & $(0.5)$ & $(0.6)$ & \\
\hline \multirow[t]{2}{*}{ Miscellaneous } & 449.6 & 317.4 & 178.4 & 444.3 & 348.3 & 212.9 & 435.6 & 352.2 & 189.7 & 0.064 \\
\hline & $(22.1)$ & $(12)$ & $(9.2)$ & $(14.6)$ & (11.8) & $(6.5)$ & $(14.6)$ & $(16.3)$ & $(18.7)$ & \\
\hline
\end{tabular}

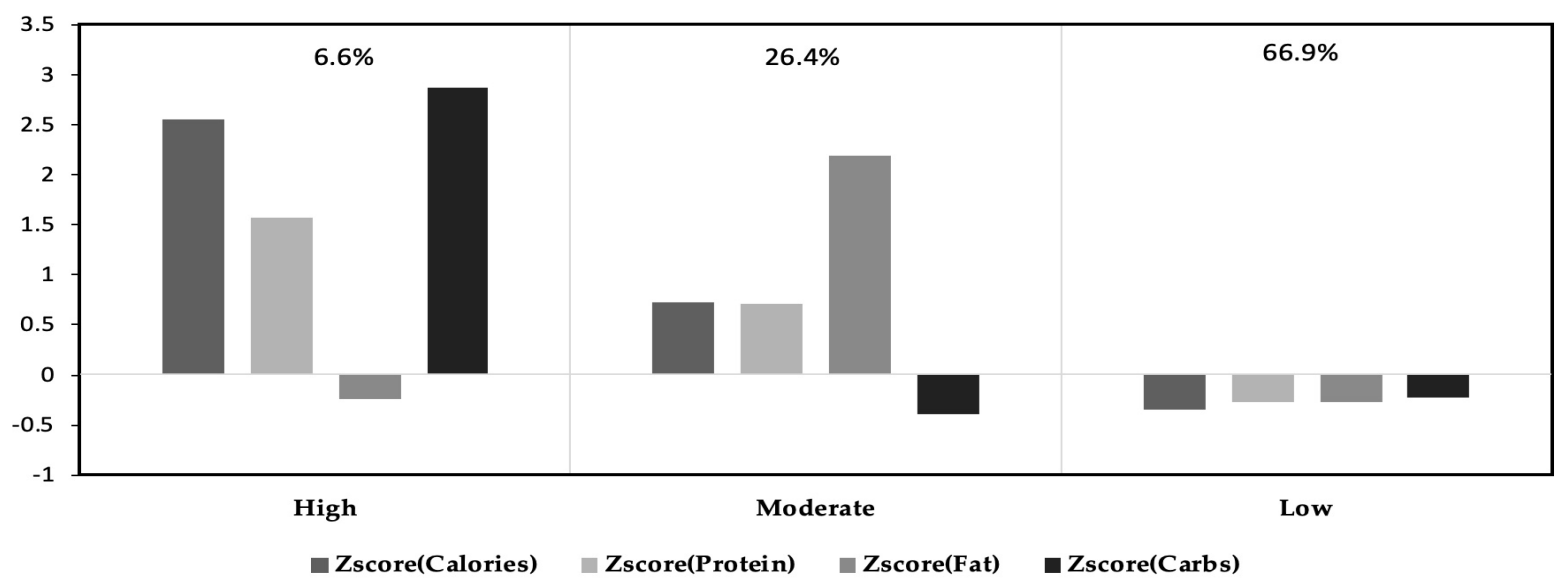

Figure 1: Average Z-score of macronutrient category K-Means clusters. 
(a)

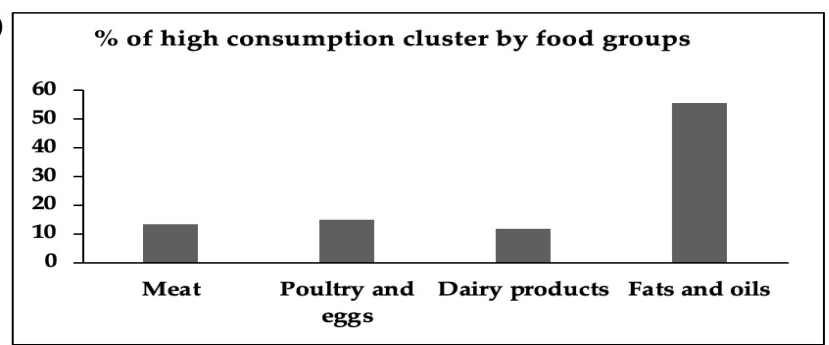

(b)

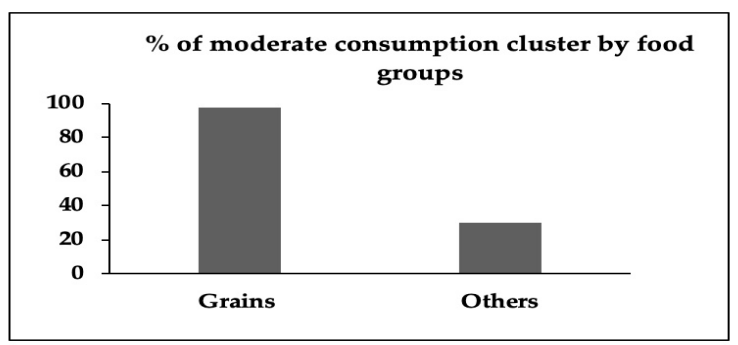

(c)

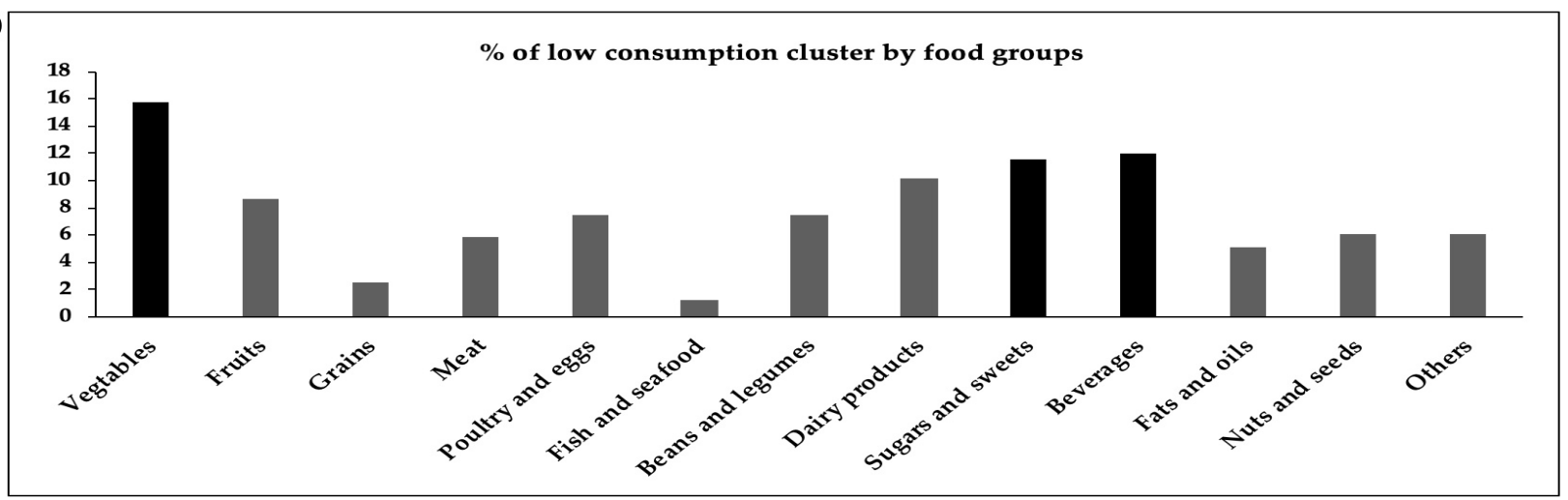

Figure 2: Percentage distribution of food groups consumption by Macronutrient category K-Means clusters.

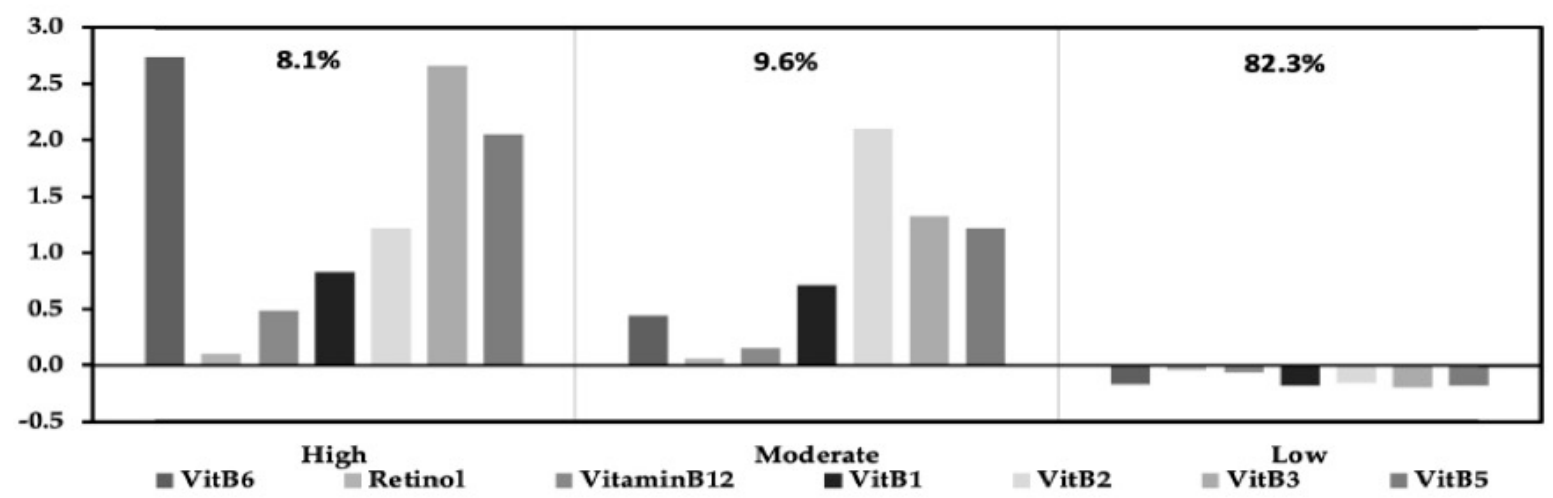

Figure 3: Average Z-Score of vitamin category K-Means clusters.

(a)

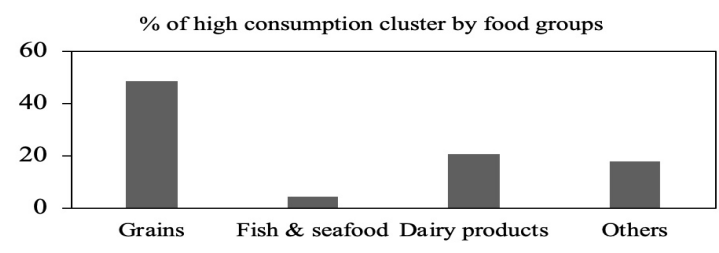

(b)

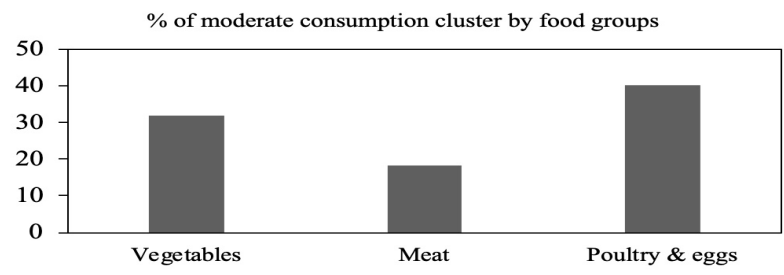

(c)

$\%$ of low consumption cluster by food groups

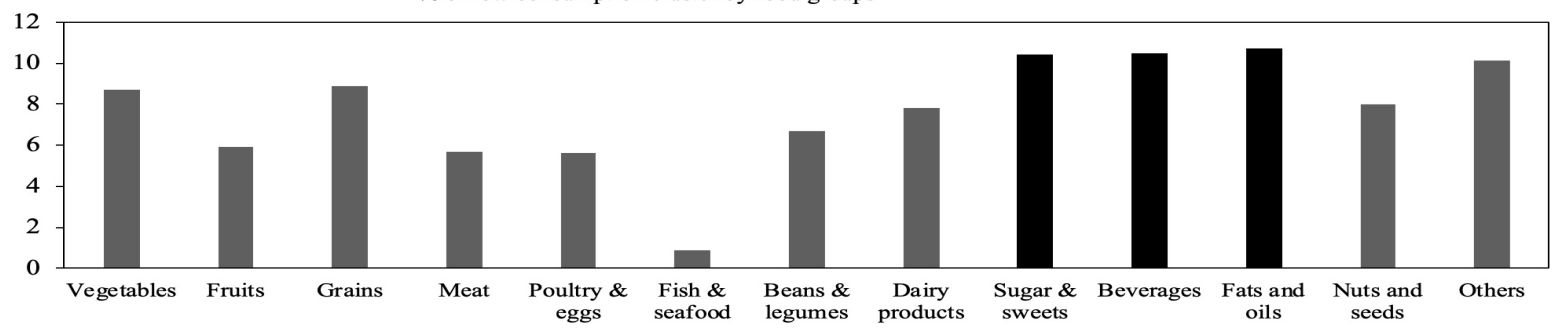

Figure4: Percentage distribution of food groups consumption by Vitamins category K-Means clusters. 
$-0.1, \quad-0.2, \quad-0.2,-0.3$, and $\quad-0.2)$ respectively. Characteristics of children described in the different clusters by the consumed food group are described in figure 4 . The vitamin high cluster consumed pattern (Figure 4a) included a high percentage of consumption of grains and dairy products (48\% and $20 \%$ ) of the sample and a significantly higher percentage of girls than boys did. In the moderate cluster consumed pattern
(Figure 4b), children consumed high vegetables, meat and poultry and eggs (31\%, 18\%, and $40 \%)$ of the sample and a significantly higher percentage of girls than boys did. In the low cluster consumed pattern (Figure 4c), children consumed more sugar, beverages, fats and oils (10.1\%, 10.2\%, and $11 \%$ ) respectively of the sample and a significantly higher percentage of girls than boys did. Figure 5 shows the characteristics of minerals clusters,

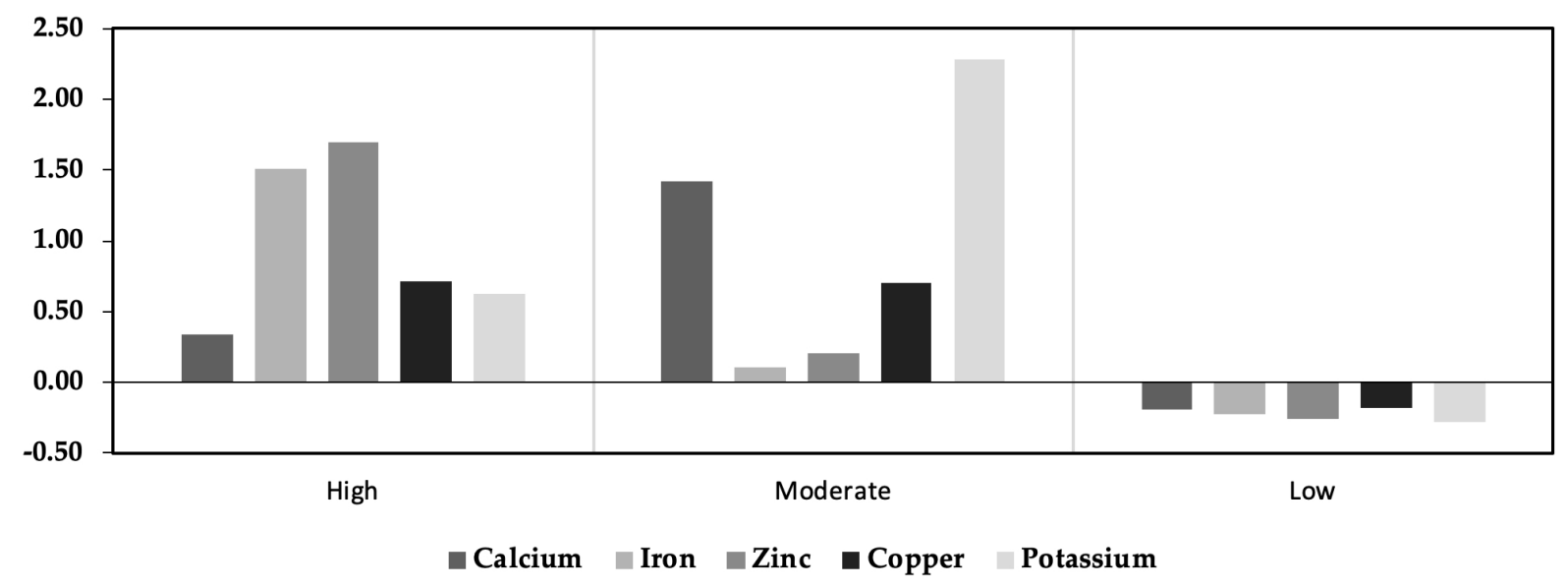

Figure 5: Average Z-Score of Minerals category K-Means Clusters.

(a)

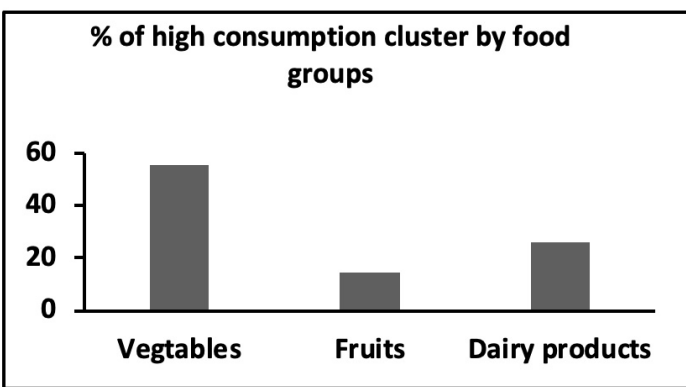

(b)

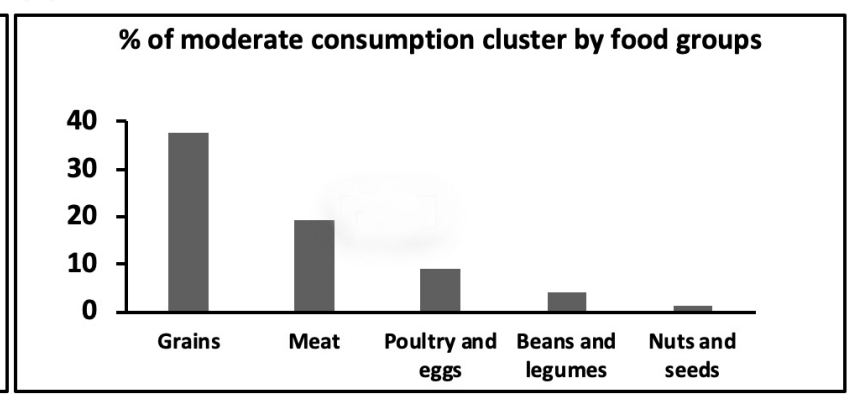

(c)

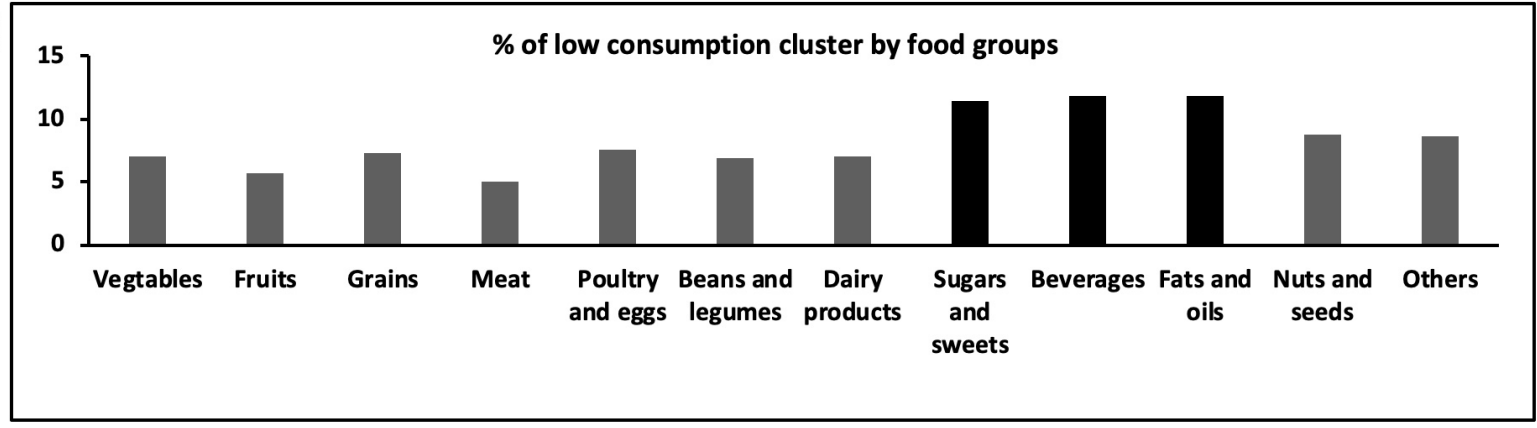

Figure 6: Percentage distribution of food groups consumption by minerals category K-Means clusters. 
the percentage distribution of high, moderate, and low clusters is (3.8\%, 18.9\%, and 77.3\%), respectively. Children aggregated into cluster 1 had high Z-Score of calcium, iron, zinc, copper, and potassium $(0.3,1.5,1.7,0.7$, and 0.6 respectively. Children in cluster 2 scored moderate Z-score in calcium, zinc,copper, and potassium (1.4, 0.21, 0.7, and 2.3). Children in cluster 3 scored negatively on calcium, iron, zinc, copper and potassium (0.2, -0.22, -0.25, -0.18, and -0.28) respectively. Characteristics of children described in the different minerals clusters by the consumed food group are described in figure 6. The minerals high cluster consumed pattern (Figure 6a) included high vegetables, fruits, and dairy products (57\%, 15\%, and $27 \%$ ) of the sample and a significantly higher percentage of girls than boys. In the moderate cluster consumed pattern (Figure 6b), children consumed a high percentage of grains and meats (48\% and 19\%), of the sample and a significantly higher percentage of girls than boys. In the low cluster consumed pattern (Figure 6c), children consumed more sugar, beverages, and fats and oils $(11.5 \%, 11.9 \%$, and $11.9 \%$ ) respectively of the sample and a significantly higher percentage of girls than boys.

\section{Discussion}

The present study involves a national sample of schoolchildren aged 11-16 years-old from West Bank to assess the frequency of food consumption, the energy and nutrient intakes, and the patterns of food groups' consumptions. The study used K-Means cluster analysis to identify the consumption patterns, nutrient intake, and lifestyle differences. This study identified the consumption clusters and adds to the literature information about Palestinian children's food groups' consumption and nutrient intakes patterns, as well as how the clusters linked with lifestyle, physical activities, and demographic variables. Among all students, about $14 \%$ were overweight or obese, and more than half of the students corresponded to a moderate level of activity. Boys reported higher activity levels than girls. Furthermore, boys spent more time in leisure time activities than girls. A high portion of students consumed poor healthy foods including take-away, sweet, beverages, and energy drinks. Boys consumed higher unhealthy food than girls.

The results are consistent with findings by other authors reporting food frequency patterns among schoolchildren (Pérez-Rodrigo et al. 2015; Gharib and Rasheed 2011). The food frequency results indicated that students consumed high portions of vegetables, sweets, and soft drinks. Boys consumed higher energy and soft drinks than girls, while girls consumed higher sweets and chocolates than boys. Girls consumed more vegetables and fruits, while boys consumed more milk and milk products. The results of 24hour recall reported the energy and nutrient intakes among school children. The study has its drawbacks of a one-time 24-hour recall that may not enough to represent the individual usual diet. However, it does represent the average daily consumption of students' groups because of the data analysis unaffected by person variation. The findings related to food frequency clusters are consistent with food consumption patterns in other studies (Desbouys et al. 2019; Williamson et al. 2020).

The mean energy intakes of Palestinian children were higher than RDA standards as well as values reported by USDA (Institute of Medicine 2009). The mean energy intake of children compared by other same-age students is a serious concern (Gharib and Rasheed 2011). High average of energy consumption contributed to high prevalence of overweight and obesity (Faught et al. 2017; Gharib and Rasheed 2011; 
James 2008; Farpour-Lambert et al. 2015; Elessi and Albaraqouni 2019; Al et al. 2009). The average protein, carbohydrate, and fat intakes were above the RDA values about USDA standards. The macronutrients consumptions increased with age due to increasing intakes of soft drinks, sweets, chocolates, and energy drinks.

It is a serious concern that around $60 \%$ of students consumed at least one soft, or energy drink per day. The increase in the consumption of sugar has been associated with overweight and obesity(Grieger, Scott, and Cobiac 2012). Besides weight problems, sugar consumption is likely to decrease children's HDL cholesterol, increase LDL cholesterol, blood glucose, and insulin concentration factors which are related to Coronary Heart Disease mortality(GerbensLeenes, Nonhebel, and Krol 2010; Gharib and Rasheed 2011; Grieger, Scott, and Cobiac 2012). Furthermore, the increase in sugar consumption will cause the nutritional inadequacy of vitamins and minerals(Gharib and Rasheed 2011).

The results obtained in the present study matched previous studies in children and adolescents that used k-Means analysis to identify food consumption patterns, dietary intakes and lifestyle variables(Landsberg et al. 2010; Magee, Caputi, and Iverson 2013; Sanchez et al. 2007; Lioret et al. 2008; Sabbe et al. 2008; Gharib and Rasheed 2011; Grieger, Scott, and Cobiac 2012; Heng and House 2018). Cluster analysis groups students' intakes into mutually exclusive groups based on the similarity in food groups consumed, allowing clusters comparisons. The food frequency k-Means clusters produced three clusters classifying the food consumption patterns. The FFQ clusters in this study are consistent with findings by other studies reporting traditional, non-traditional and mixed consumption patterns that combine healthy and unhealthy food groups and assessed the relationship with physical activities and lifestyle.
Several studies have identified a healthier or traditional food consumption in children, with higher scores of vegetables, fruits, and dairy products(Rathnayaka, Selvanathan, and Selvanathan 2019; Kunin-Batson et al. 2015; Heng and House 2018; Landsberg et al. 2010). Other studies described non-traditional or mixed food consumption as unhealthy consumption patterns with high scores of soft drinks, sweets, and chocolates, and energy drinks(Gharib and Rasheed 2011; Magee, Caputi, and Iverson 2013; Grieger, Scott, and Cobiac 2012; Sanchez et al. 2007). Numerous studies assessed the combination clustering with lifestyle, physical activities, and a healthy diet(Aguilà et al. 2017; Magee, Caputi, and Iverson 2013; Sanchez et al. 2007; Lioret et al. 2008; Landsberg et al. 2010). Leech et al. (Rebecca M. Leech, McNaughton, and Timperio 2014)conducted a systematic review on the clustering of diet, physical activity, and sedentary behavior among children and adolescents aged 9-21 years, his study found that most of children and adolescents had mixed consumption pattern of healthy and unhealthy food. Another study also identified that a higher portion of girls aged 10-12 years old falls in low physical activity (Sanchez et al. 2007).

In our study, Z-scores K-Means clustering was used to identify the energy and nutrient intakes clusters among Palestinian schoolchildren. Three nutrient intakes categories were found, the macronutrient, vitamins, and minerals. Several studies used cluster analysis to identify the relationship between dietary intakes pattern and lifestyle (Jongenelis et al. 2020; Kulik et al. 2019; Pala, Reisch, and Lissner 2019; Shah et al. 2019; Nubani-Husseini et al. 2016).

The study extended other similar studies and identified three clusters (high, moderate and low) consumption patterns (Niermann, Spengler, and Gubbels 2018; Wirfält and Jeffery 1997; Grieger, Scott, and Cobiac 2012; Landsberg et al. 2010; Rebecca 
M. Leech, McNaughton, and Timperio 2014; Sabbe et al. 2008). The macronutrient group identified approximately $81 \%$ of students with the negative and low z-scores cluster. Students in this cluster consumed more vegetables, sugar, and beverages. The vitamin group identified approximately $82 \%$ of students with low and negative scores, students in this cluster consumed more sugar, beverages, fats, and oils and vegetables. The minerals cluster identified approximately $77 \%$ of students with low and negative scores, the students consumed more sugar, beverages, and fats and oils.

It is expected that students in these ages consumed higher intake of sugar and soft-drinks and lower healthy nutrient intakes. Interestingly, there was a significant difference in nutrient intakes clusters with gender. Girls have a significant difference in consuming more vegetables in macronutrient groups and more sugar and chocolates in vitamins and minerals groups. The results in this study extended the results of other previous studies using cluster analysis that focused on dietary intakes, lifestyles, and sociodemographic status (R. M. Leech, McNaughton, and Timperio 2014; Gubbels, van Assema, and Kremers 2013; Hosseini et al. 2019; Sanchez et al. 2007; Rebecca M. Leech, McNaughton, and Timperio 2014; Sabbe et al. 2008). These studies have identified that schoolchildren consumed high energy food intakes and more unhealthy food groups, similar to these studies the Palestinian children highly exposed to takeaway food and soft-drinks, chocolates and energy drinks. The widespread of take-away food and sugar and energy drinks increased the students' accessibility to unhealthy food.

Difference between boys and girls in average grams consumption by food group dietary pattern indicated a significant difference by gender distribution, the boys consumed higher grams in vegetables, fruits, grain, meat, dairy products, and beverages, while girls had higher consumption in beans and legumes, fats and oils, and sugars and sweets groups. The food group consumption by gender was reported by other authors(Vasileska and Rechkoska 2012; Desbouys et al. 2019; Gharib and Rasheed 2011; Grieger, Scott, and Cobiac 2012). Gender difference in daily consumption was found, boys consumed higher vegetables, grain, beans and legumes, meat and poultry and eggs. Contradictory results have been reported regarding sugars and sweets, and fats and oils (Gharib and Rasheed 2011), boys consumed higher grams than girls, however, gender significant difference was found(Grieger, Scott, and Cobiac 2012).

The strengths of this study were found in the design of 24-hour food recall data. Food consumption data were analyzed using the Palestinian food recipes database and the Palestinian food composition table developed by ANAHRI. The food consumption classification according to the international food groups categories using energy and grams distribution was the first study among Palestinian schoolchildren. The cluster analysis using food frequency and nutrient intakes allowed us to identify the actual dietary patterns without any predefined criteria and their difference with physical activities, lifestyle and gender provided a comprehensive perspective.

There are some limitations to the present study, including the cross-sectional approach. Therefore, it provides evidence for the association but not causal relationships. Measures of food frequency consumption and physical activity relied on self-reports and were possibly biased, although a careful multistep quality control procedure was implemented under the supervision of the Ministry of the Education team to minimize bias. However, misreporting can influence the potential association with study variables. Cluster analysis is an observed method 
of defining similar groups of individuals and is particularly appropriate for identifying groups that could benefit from interventions. A series of particular actions are required when carrying out a cluster analysis, including the selection of food groups, the variables used to determine clusters, especially the nutrient intakes clusters (e.g. grams of consumption, frequency of consumption, vitamins, and minerals), the number of clusters, and the clusters. These actions may not be appropriate in different populations. Thus, the repeatability and generalization of cluster analysis in different populations are limited. However, we performed the same cluster analysis methodology in the study population using the 24-hour face to face interview data, in which three similar clusters found. Using a single day's food intake may also misclassify individuals into a different cluster than what may occur after a longer-term intake. Finally, K-Means analysis is a procedure commonly used to identify dietary patterns and analyze the clustering of lifestyle. However, long term intake may provide more adequate clusters and better to identify patterns and clusters.

\section{Conclusion}

Three food consumption patterns were identified, traditional, none-traditional, and mixed, the traditional is close to the Mediterranean diet. Energy and nutrient intakes cluster analysis classified students into three groups with three clusters each. The macronutrient group, vitamins, and minerals. The clusters were identified as high, moderate, and low consumption scores. The lifestyle and physical activity identified two groups of students, unhealthier lifestyle patterns with low physical activity and high consumption of unhealthy foods; and healthier lifestyle patterns with high physical activity and high consumption of healthy foods. The significant differences were found in children into different clusters. Future research using larger samples is needed to further examine how food groups consumption and lifestyle patterns of nutrient intakes track over time and influence on children's health. These cluster analyses are helpful to identify Palestinian children's consumption patterns and act as a baseline for potential intervention strategies.

\section{Declarations}

Ethics approval and consent to participate The study received ethics approval from the Health Research Ethics Boards at the Ministry of Education and Al-Quds University. Written informed consent was obtained from all parents and written assent was obtained from children.

\section{Availability of data and materials}

The datasets generated and/or analyzed during the current study are not publicly available due to the current use by other Ph.D. students but are available from the corresponding author on reasonable request

\section{Author Contributions}

Conceptualization R.Q., Z.A, and H.S; methodology, validation, formal analysis, and writing-review and editing, R.Q., D.A, and Z.A.; review and editing Z.A and H.S.; writing-original draft preparation, R.Q; project administration, R.Q and Z.A.; data curation, H.T, and R.A.Competing interests: The authors declare no conflict of interest. The funders had no role in the design of the study; in the collection, analyses, or interpretation of data; in the writing of the manuscript; or in the decision to publish the results.

Funding: The analysis presented in this paper is part of the wider project "Determinants of Cognitive Development in Deprived Environments: Evidence from the West Bank" funded by the 
German Research Foundation (DFG) under grant number $J \cup$ 2769/2. We are grateful to the PA Ministry of Education, test administrators, and the students who participated in the study and their parents for their time and effort.

Acknowledgments: The authors wish to thank the Ministry of Education, Palestine for permitting us to conduct the study, the children and their parents for their patience and all field workers. Authors wish to thank Mohammad Remawi and Suzan Tutah for their support in data collection and we are also grateful to Sameh Al Halaq for his contributions.

\section{References}

Abdeen, Z., C. Jildeh, S. Dkeideek, R. Qasrawi, I. Ghannam, and H. Al Sabbah. 2012. "Overweight and Obesity among Palestinian Adults: Analyses of the Anthropometric Data from the First National Health and Nutrition Survey (19992000)." Journal of Obesity 2012. https://doi. org/10.1155/2012/213547.

Abdeen, Ziad, Anat Brunstein Klomek, Ora Nakash, Nabil Shibli, Maayan Nagar, Hazem Agha, Sameh Hallaq, Yaniv Kanat Maymon, Hendrik Juerges, and Itzhak Levav. 2018. "The Association between Political Violence and the Connection between Bullying and Suicidality among Palestinian Youth." Suicide and Life Threatening Behavior 48 (1): 95-104.

Aboul-Enein, B H, J Bernstein, and A C Neary. 2017. "Dietary Transition and Obesity in Selected Arabic-Speaking Countries: A Review of the Current Evidence." Eastern Mediterranean Health Journal 22 (10): 763-70.

Aguilà, Queralt, Maria Àngels Ramón, Susana Matesanz, Ramon Vilatimó, Irene del Moral, Carles Brotons, and Àngels Ulied. 2017. "Assessment Study of the Nutritional Status, Eating Habits and Physical Activity of the Schooled Population of Centelles, Hostalets de Balenyà and Sant Martí de Centelles (ALIN 2014 Study)." Endocrinología, Diabetes y Nutrición (English Ed.) 64 (3): 138-45. https://doi.org/10.1016/j.endien.2017.01.001.

Ahuja, J K A, Janice B Montville, Grace Omolewa-Tomobi, Kaushalya Y Heendeniya, Carrie L Martin, Lois C Steinfeldt, Jaswinder Anand, Meghan E Adler, Randy P LaComb, and Alanna J Moshfegh. 2012. "USDA Food and Nutrient Database for Dietary Studies, 5.0-Documentation and User Guide."
US Department of Agriculture, Agricultural Research Service, Food Surveys Research Group: Beltsville, MD, USA.

Al, H Sabbah, C Vereecken, Z Abdeen, E Coats, and L Maes. 2009. "Associations of Overweight and of Weight Dissatisfaction among Palestinian Adolescents: Findings from the National Study of Palestinian Schoolchildren (HBSC-WBG2004)." Journal of Human Nutrition and Dietetics: The Official Journal of the British Dietetic Association 22 (1): 40-49.

Alavian, Seyed-Moayed, Mohammad Esmaeil Motlagh, Gelayol Ardalan, Molouk Motaghian, Amir Hossein Davarpanah, and Roya Kelishadi. 2008. "Hypertriglyceridemic Waist Phenotype and Associated Lifestyle Factors in a National Population of Youths: CASPIAN Study." Journal of Tropical Pediatrics 54 (3): 169-77.

Aounallah-Skhiri, Hajer, Pierre Traissac, Jalila El Ati, Sabrina Eymard-Duvernay, Edwige Landais, Noureddine Achour, Francis Delpeuch, Habiba Ben Romdhane, and Bernard Maire. 2011. "Nutrition Transition among Adolescents of a South-Mediterranean Country: Dietary Patterns, Association with Socio-Economic Factors, Overweight and Blood Pressure. A CrossSectional Study in Tunisia." Nutrition Journal 10 (1): 1-17. https://doi.org/10.1186/1475-2891-10-38.

Desbouys, Lucille, Karin De Ridder, Manon Rouche, and Katia Castetbon. 2019. "Food Consumption in Adolescents and Young Adults: Age-Specific Socio-Economic and Cultural Disparities (Belgian Food Consumption Survey 2014)." Nutrients 11 (7). https://doi.org/10.3390/ nu11071520.

Elessi, Khamis, and Loai Albaraqouni. 2019. "Prevalence of Obesity and Overweight in Palestine: A Systematic Review." The Lancet 393: S20. https://doi.org/10.1016/ s0140-6736(19)30606-3.

Farpour-Lambert, Nathalie J., Jennifer L. Baker, Maria Hassapidou, Jens Christian Holm, Paulina Nowicka, Grace O"malley, and Ram Weiss. 2015. "Childhood Obesity Is a Chronic Disease Demanding Specific Health Care - A Position Statement from the Childhood Obesity Task Force (COTF) of the European Association for the Study of Obesity (EASO)." Obesity Facts 8 (5): 342-49. https://doi.org/10.1159/000441483.

Faught, Erin L., Patty L. Williams, Noreen D. Willows, Mark Asbridge, and Paul J. Veugelers. 2017. "The Association between Food Insecurity and Academic Achievement in Canadian School-Aged Children." Public Health Nutrition 20 (15): 277885. https://doi.org/10.1017/\$1368980017001562.

Frank, G C, T A Nicklas, L S Webber, C Major, J F Miller, 
and G S Berenson. 1992. "A Food Frequency Questionnaire for Adolescents: Defining Eating Patterns." Journal of the American Dietetic Association 92 (3): 313-18.

Gerbens-Leenes, P. W., S. Nonhebel, and M. S. Krol. 2010. "Food Consumption Patterns and Economic Growth. Increasing Affluence and the Use of Natural Resources." Appetite 55 (3): 597-608. https://doi. org/10.1016/j.appet.2010.09.013.

Gharib, Nadia, and Parveen Rasheed. 2011. "Energy and Macronutrient Intake and Dietary Pattern among School Children in Bahrain: A Cross-Sectional Study." Nutrition Journal 10 (1): 1-12. https://doi. org/10.1186/1475-2891-10-62.

Grieger, J. A., J. Scott, and L. Cobiac. 2012. “Cluster Analysis and Food Group Consumption in a National Sample of Australian Girls." Journal of Human Nutrition and Dietetics 25 (1): 75-86. https://doi. org/10.1111/j.1365-277X.2011.01195.X.

Gubbels, Jessica S., Patricia van Assema, and Stef P.J. Kremers. 2013. "Physical Activity, Sedentary Behavior, and Dietary Patterns among Children." Current Nutrition Reports 2 (2): 105-12. https://doi. org/10.1007/s13668-013-0042-6.

Heng, Yan, and Lisa A. House. 2018. "Cluster Analysis for Fruit Consumption Patterns: An International Study." British Food Journal 120 (9): 1942-52. https:// doi.org/10.1108/BFJ-01-2018-0014.

Hosseini, Syed Hamzeh, Yanni Papanikolaou, Naorin Isalm, Patil Rashmi, Arash Shamloo, and Hassan Vatanparast. 2019. "Consumption Patterns of Grain-Based Foods among Children and Adolescents in Canada: Evidence from Canadian Community Health Survey-Nutrition 2015." Nutrients 11 (3). https://doi.org/10.3390/nu11030623.

Institute of Medicine. 2009. School Meals: Building Blocks for Healthy Children In. http://www.iom. edu/Activities/Nutrition/SchoolMeals/2009OCT-20.aspx.

James, W. P.T. 2008. "The Epidemiology of Obesity: The Size of the Problem." Journal of Internal Medicine 263 (4): 336-52. https://doi.org/10.1111/ j.1365-2796.2008.01922.x.

Jongenelis, Michelle I, Belinda Morley, Iain S Pratt, and Zenobia Talati. 2020. "Diet Quality in Children: A Function of Grandparents' Feeding Practices?” Food Quality and Preference, 103899.

Kulik, Noel, Erica M Thomas, Mariane M Fahlman, Alex C Garn, Erin E Centeio, Cheryl L Somers, and Nathan McCaughtry. 2019. "Dietary Self-Efficacy and Dietary Intake by Race/Ethnicity among Elementary School Children." Health Education Journal 78 (4): 486-93.

Kunin-Batson, Alicia S., Elisabeth M. Seburg, A. Lauren
Crain, Meghan M. Jaka, Shelby L. Langer, Rona L. Levy, and Nancy E. Sherwood. 2015. "Household Factors, Family Behavior Patterns, and Adherence to Dietary and Physical Activity Guidelines among Children at Risk for Obesity." Journal of Nutrition Education and Behavior 47 (3): 206-215. e1. https://doi.org/10.1016/j.jneb.2015.01.002.

Landsberg, Beate, Sandra Plachta-Danielzik, Dominique Lange, Maike Johannsen, Jasmin Seiberl, and Manfred James Müller. 2010. "Clustering of Lifestyle Factors and Association with Overweight in Adolescents of the Kiel Obesity Prevention Study." Public Health Nutrition 13 (10 A): 1708-15. https://doi.org/10.1017/ S1368980010002260.

Lee, Robert D. 1997. "Nutribase Nutrition Manager." Journal of the Academy of Nutrition and Dietetics 97 (2): 219.

Leech, R. M., S. A. McNaughton, and A. Timperio. 2014. "Clustering of Children's Obesity-Related Behaviours: Associations with Sociodemographic Indicators." European Journal of Clinical Nutrition 68 (5): 623-28. https://doi.org/10.1038/ejcn.2013.295.

Leech, Rebecca M., Sarah A. McNaughton, and Anna Timperio. 2014. "The Clustering of Diet, Physical Activity and Sedentary Behavior in Children and Adolescents: A Review." International Journal of Behavioral Nutrition and Physical Activity 11 (1): 1-9. https://doi.org/10.1186/1479-5868-11-4.

Lioret, Sandrine, Mathilde Touvier, Lionel Lafay, Jean-Luc Volatier, and Bernard Maire. 2008. "Dietary and Physical Activity Patterns in French Children Are Related to Overweight and Socioeconomic Status." The Journal of Nutrition 138 (1): 101-7. https://doi. org/10.1093/jn/138.1.101.

Magee, Christopher A., Peter Caputi, and Don C. Iverson. 2013. "Patterns of Health Behaviours Predict Obesity in Australian Children." Journal of Paediatrics and Child Health 49 (4): 291-96. https://doi.org/10.1111/jpc.12163.

Mehio Sibai, Abla, Lara Nasreddine, Ali H. Mokdad, Nada Adra, Maya Tabet, and Nahla Hwalla. 2011. "Nutrition Transition and Cardiovascular Disease Risk Factors in Middle East and North Africa Countries: Reviewing the Evidence." Annals of Nutrition and Metabolism 57 (3-4): 193-203. https://doi.org/10.1159/000321527.

Mikki, Nahed, Hanan F Abdul-Rahim, Faisal Awartani, and Gerd Holmboe-Ottesen. 2009. "Prevalence and Sociodemographic Correlates of Stunting, Underweight, and Overweight among Palestinian School Adolescents (13-15 Years) in Two Major Governorates in the West Bank." BMC Public 
Health 9 (1): 485

Mikki, Nahed, Hanan F Abdul-Rahim, Zumin Shi, and Gerd Holmboe-Ottesen. 2010. "Dietary Habits of Palestinian Adolescents and Associated Sociodemographic Characteristics in Ramallah, Nablus and Hebron Governorates." Public Health Nutrition 13 (9): 1419-29.

Nguyen, Phuong H., Garrett Strizich, Alyssa Lowe, Hieu Nguyen, Hoa Pham, Truong V. Truong, Son Nguyen, Reynaldo Martorell, and Usha Ramakrishnan. 2013. "Food Consumption Patterns and Associated Factors among Vietnamese Women of Reproductive Age." Nutrition Journal 12 (1): 1-11. https://doi.org/10.1186/1475-2891-12126.

Niermann, Christina Y. N., Sarah Spengler, and Jessica S. Gubbels. 2018. "Physical Activity, Screen Time, and Dietary Intake in Families: A Cluster-Analysis With Mother-Father-Child Triads." Frontiers in Public Health 6 (September): 1-12. https://doi.org/10.3389/ fpubh.2018.00276.

Nishtar, Sania, Peter Gluckman, and Timothy Armstrong. 2016. "Ending Childhood Obesity: A Time for Action.” The Lancet 387 (10021): 825-27.https://doi. org/10.1016/S0140-6736(16)00140-9.

Nubani-Husseini, Maha, Elliot Berry, Ziad Abdeen, and Milka Donchin. 2016. "Dietary Patterns and Physical Activity among Palestinian Female Schoolchildren in East Jerusalem." South Eastern European Journal of Public Health (SEEJPH).

Pala, Valeria, Lucia A Reisch, and Lauren Lissner. 2019. "Dietary Behaviour in Children, Adolescents and Families: The Eating Habits Questionnaire (EHQ)." In Instruments for Health Surveys in Children and Adolescents, 103-33. Springer.

Pérez-Rodrigo, Carmen, Ángel Gil, Marcela GonzálezGross, Rosa M. Ortega, Lluis Serra-Majem, Gregorio Varela-Moreiras, and Javier ArancetaBartrina. 2015. "Clustering of Dietary Patterns, Lifestyles, and Overweight among Spanish Children and Adolescents in the ANIBES Study." Nutrients 8 (1): 1-17. https://doi.org/10.3390/ nu8010011.

Rahman, S M Tajdit, Md Daharul Islam, Ranajit Sen Chowdhury, and Abida Tarannum. 2020. "Childhood Obesity: Nutritional Transition of Bangladesh.” Bangladesh Journal of Medicine 31 (1): 37-38.

Rathnayaka, Shashika D., E. A.Selva Selvanathan, and Saroja Selvanathan. 2019. "Consumption Patterns in Sri Lanka: A Decomposition Analysis.” Applied Economics 51 (37): 4056-72. https://doi.org/10.1080/ 00036846.2019 .1588950$.

Roblin, Lynn. 2007. “Childhood Obesity: Food, Nutrient, and Eating-Habit Trends and Influences." Applied Physiology, Nutrition, and Metabolism 32 (4): 635-45.

Sabbe, Dieter, I. De Bourdeaudhuij, E. Legiest, and L. Maes. 2008. "A Cluster-Analytical Approach towards Physical Activity and Eating Habits among 10-Year-Old Children." Health Education Research 23 (5): 753-62. https://doi.org/10.1093/ her/cyl135.

Salameh, Pascale, Lamis Jomaa, Carine Issa, Ghada Farhat, Joseph Salamé, Nina Zeidan, Isabelle Baldi, et al. 2014. "Assessment of Dietary Intake Patterns and Their Correlates among University Students in Lebanon." Frontiers in Public Health 2 (OCT): 1-12. https://doi.org/10.3389/ fpubh.2014.00185.

Sanchez, Alvaro, Gregory J. Norman, James F. Sallis, Karen J. Calfas, John Cella, and Kevin Patrick. 2007. "Patterns and Correlates of Physical Activity and Nutrition Behaviors in Adolescents." American Journal of Preventive Medicine 32 (2): 124-30. https://doi.org/10.1016/j.amepre.2006.10.012.

Shah, Farhana Jabeen, Syeda Lala Rukh Saba Shah, Hamid Hussain, Syeda Gulrukh Saba Shah, Muhammad Hamayun, and Muhammad Ayub Roz. 2019. "Association of Dietary Habits, Physical Activity and Sedentary Life Style with Obesity in School Going Children and Adolescent of Peshawar." Journal of Saidu Medical College 9 (1).

Tariq, Rukiya, Maryam Shahid, and Kalsoom Tariq. 2018. "OVERWEIGHT AND OBESITY: SOCIODEMOGRAPHIC FACTORS AND DISEASES CAUSING OVERWEIGHT AND OBESITY AMONG 25-60 YEARS WOMEN IN LAHORE, PAKISTAN." Professional Medical Journal 25 (5).

Vasileska, Angela, and Gordana Rechkoska. 2012. "Global and Regional Food Consumption Patterns and Trends." Procedia - Social and Behavioral Sciences 44: 363-69. https://doi. org/10.1016/j.sbspro.2012.05.040.

Waters, Elizabeth, Andrea De Silva-Sanigorski, Belinda J. Burford, Tamara Brown, Karen J. Campbell, Yang Gao, Rebecca Armstrong, Lauren Prosser, and Carolyn D. Summerbell. 2014. "Interventions for Preventing Obesity in Children.” Sao Paulo Medical Journal 132 (2): 128. https://doi.org/10.1590/15163180.20141322 T2.

Williamson, Victoria G., Abhaya Dilip, Jackson R. Dillard, Jane Morgan-Daniel, Alexandra M. Lee, and Michelle I. Cardel. 2020. "The Influence of Socioeconomic Status on Snacking and Weight among Adolescents: A Scoping Review." Nutrients 12 (1): 1-18. https://doi.org/10.3390/ 
nu12010167.

Wirfält, A. K.Elisabet, and Robert W. Jeffery. 1997. “Using Cluster Analysis to Examine Dietary Patterns: Nutrient Intakes, Gender, and Weight Status Differ across Food Pattern Clusters." Journal of the American Dietetic Association. https://doi. org/10.1016/S0002-8223(97)00071-0.
Zhou, B., Y. Lu, K. Hajifathalian, J. Bentham, M. Di Cesare, G. Danaei, H. Bixby, et al. 2016. "Worldwide Trends in Diabetes since 1980: A Pooled Analysis of 751 Population-Based Studies with 4.4 Million Participants.” The Lancet 387 (10027). https://doi. org/10.1016/S0140-6736(16)00618-8. 